\title{
Tobacco, alcohol and illicit drug use among Aboriginal youth living off-reserve: results from the Youth Smoking Survey
}

\author{
Tara Elton-Marshall PhD, Scott T. Leatherdale PhD, Robin Burkhalter MMath
}

Competing interests: None declared.

This article has been peer reviewed.

\section{Correspondence to:}

Dr. Scott T. Leatherdale, scott.leatherdale@cancercare .on.ca

CMAJ 2011. DOI:10.1503 /cmaj.101913

\begin{abstract}
Background: Despite the high prevalence of smoking among Aboriginal youth, there is a paucity of research related to tobacco use and other risk behaviours among Aboriginal youth living off-reserve in Canada. We used data from the national Youth Smoking Survey to characterize non-traditional tobacco use, exposure to second-hand smoke, and alcohol and drug use among Aboriginal youth living off-reserve. We examined whether these youth were at increased health risk compared with non-Aboriginal youth.
\end{abstract}

Methods: We examined cigarette smoking behaviour, use of other tobacco products, use of alcohol and other drugs, and exposure to second-hand smoke among 2620 Aboriginal youth living off-reserve and 26223 non-Aboriginal youth in grades 9 to 12 who participated in the 2008/09 Youth Smoking Survey. ompared with the general population in Canada, Aboriginal youth start smoking earlier ${ }^{1}$ and have a higher prevalence of smoking, ${ }^{1-3}$ with female Aboriginals at greatest risk. ${ }^{1}$ Research has also shown that Aboriginal youth have high rates of binge drinking ${ }^{1}$ and are more likely than non-Aboriginal youth to use marijuana. ${ }^{4}$

Despite the high prevalence of smoking among Aboriginal youth in Canada, there is a paucity of research related to their patterns of tobacco use, especially among Aboriginals living off-reserve. ${ }^{5}$ Most Aboriginals in Canada live off-reserve, ${ }^{6}$ and those 15 years of age and older are more likely than non-Aboriginals to have chronic health conditions, to drink heavily and to smoke. ${ }^{7}$ Given that the Canadian Tobacco Control Strategy emphasizes targeting youth, young adults, First Nations, Inuit and other Aboriginal groups ${ }^{8}$ a better understanding of tobacco use among Aboriginal youth living offreserve is required.

We conducted this study to examine patterns of tobacco use, exposure to second-hand smoke and the prevalence of alcohol and other drug use
Results: The prevalence of current smoking among the Aboriginal youth was more than double that among non-Aboriginal youth $(24.9 \%$ v. $10.4 \%)$. Aboriginal youth also had a higher prevalence of regular exposure to second-hand smoke at home (37.3\% v. $19.7 \%)$ and in cars $(51.0 \%$ v. $30.3 \%)$. Aboriginal youth were more likely than non-Aboriginal youth to be current smokers, to be regularly exposed to second-hand smoke, to have tried marijuana and other illicit drugs, and to engage in binge drinking. They were less likely than nonAboriginal youth to have tried to quit smoking.

Interpretation: Current national estimates of smoking, and alcohol and illicit drug use among youth underestimate the prevalence of these behaviours among Aboriginal youth living offreserve. Our findings highlight the need for culturally appropriate prevention and cessation policies and programs for this at-risk population. among Aboriginal youth living off-reserve. We compared these data with those for nonAboriginal youth using nationally representative data from the 2008/09 Youth Smoking Survey.

\section{Methods}

\section{Study design}

We obtained cross-sectional data for 28843 youth in grades 9 to 12 who responded to the 2008/09 Youth Smoking Survey. ${ }^{9}$ The Youth Smoking Survey is the only nationally representative school-based survey of youth in Canada that collects data on their smoking behaviour. Consistent with previous survey waves (1994, $2002,2004 / 05$ and 2006/07), the target population for the 2008/09 wave was youth attending public and private schools in Canada's 10 provinces. Youth residing in the Yukon Territory, Nunavut and the Northwest Territories are excluded, as are youth living in institutions or on First Nation reserves and youth attending special schools or schools on military bases.

The sample uses a stratified design based on the health region's prevalence of smoking (above 
or below the median). In each province, schools are then randomly selected to participate, with probabilities proportional to the total enrolment in their school boards. The number of private schools randomly selected to participate is proportional to the number of students enrolled in private schools in each province compared with the number in public schools.

Within each participating school, all students in grades 6 to 12 are eligible to complete the survey. We focused our study on data for students in grades 9 to 12 , in part because information on drug and alcohol use was not collected for youth in grade 6 and because adolescents in secondary school are more likely than youth in earlier grades to use tobacco, alcohol and illicit drugs. Secondary school students are also expected to be more homogeneous. Future research will examine tobacco use among presecondary students separately.

Research ethics approval for the Youth Smoking Survey was obtained from the University of Waterloo Human Research Ethics Committee and local institutional review boards where required. The overall response rate to the 2008/09 Youth Smoking Survey was 84\% at the school board level, 59\% at the school level and $73 \%$ at the student level. Detailed information about the 2008/09 survey sample design, methods and response rates are available at www.yss .uwaterloo.ca/results/yss08_user_guide.pdf.

\section{Measures}

The measures used for our study are consistent with those in previous studies using data from the Youth Smoking Survey. ${ }^{9-12}$

To determine Aboriginal status, respondents are asked "Are you an aboriginal person?" (yes, First Nations; yes, Métis; yes, Inuit; or no, I am not an aboriginal person). Respondents are asked to report their current grade, sex and geographic region, which is categorized as British Columbia, Prairies (Alberta, Saskatchewan and Manitoba), Ontario, Quebec and Atlantic Canada (New Brunswick, Prince Edward Island, Nova Scotia, and Newfoundland and Labrador). To determine personal income, the survey asks "How much money do you usually get each week to spend on yourself or save?" (\$0, $\$ 1-5$, \$6-10, \$11-20, \$21-40, \$41-100, more than $\$ 100$, or don't know how much). Response categories are collapsed (\$0, $\$ 1-20, \$ 20$ or more, and don't know how much).

Consistent with Health Canada's definitions of smoking status, ${ }^{9}$ a current smoker is someone who has smoked at least 100 cigarettes in his or her lifetime and who has smoked at least one whole cigarette in the past 30 days. A former smoker has smoked at least 100 cigarettes in his or her lifetime but has not smoked in the past 30 days. A nonsmoker has not smoked 100 or more cigarettes in his or her lifetime but may have smoked one whole cigarette. Susceptibility to future smoking among those who reported never having smoked (never smoked a cigarette, not even a puff) is measured using the validated algorithm of Pierce and colleagues. ${ }^{13}$ Current smokers are asked to report whether they had ever tried to quit $(0=$ never tried, $1=$ tried to quit at least once).

To determine types of tobacco products used, respondents are asked "Have you ever tried any of the following?" and "In the last 30 days, did you use any of the following?" for the following tobacco products: pipe tobacco; cigarillos or little cigars (plain or flavoured); cigars (plain or flavoured, not including cigarillos or little cigars); roll-your-own cigarettes (tobacco only); smokeless tobacco (chewing tobacco, pinch, snuff or snus); and nicotine patches, nicotine gum or nicotine lozenges.

To determine exposure to second-hand smoke, respondents are asked to report the number of people who smoke inside their home every day or almost every day and how many days (in the last week) they rode in a car with someone who was smoking.

The survey also measured alcohol and marijuana use in the last 12 months; age at which alcohol and marijuana were first tried; frequency of binge drinking (five or more drinks on one occasion) in the last 12 months; and use of illicit drugs (e.g., amphetamines, hallucinogens and heroin).

\section{Survey weights}

In the first stage, a weight is created to account for the school selection within the health region and school strata. A second weight is calculated to adjust for student nonresponse. Finally, the weights are calibrated to the provincial distribution of sex and grade so that the total of the survey weights by sex, grade and province equals the actual enrolments in those groups.

\section{Statistical analysis}

To test for differences between Aboriginal youth living off-reserve and non-Aboriginal youth (and for differences by sex), we used a weighted $\chi^{2}$ test. We used $t$ tests to determine the difference in average age at first try of alcohol and marijuana between Aboriginal and non-Aboriginal youth. Using weighted logistic regression analyses, we tested whether Aboriginal status predicted key outcome variables after controlling for demographic variables. We used survey weights to adjust for nonresponse between 
provinces and groups (thereby minimizing any bias in the analyses caused by differential response rates across regions or groups) and to provide population-level prevalence estimates.

\section{Results}

Of the 28843 respondents in grades 9 to 12 who answered the item about Aboriginal status, 2620 $(9.1 \%)$ identified themselves as Aboriginal: 1408 $(53.7 \%)$ were First Nations, 962 (36.7\%) were Métis and 250 were Inuit $(9.5 \%)$. Table 1 pre- sents the sample characteristics of the Aboriginal and non-Aboriginal youth in our sample by sex.

\section{Tobacco use}

Overall, $24.9 \%$ of the Aboriginal respondents reported that they were current smokers, $2.6 \%$ were former smokers, and $72.4 \%$ were nonsmokers (Table 1). The corresponding proportions among the non-Aboriginal respondents were $10.4 \%, 1.5 \%$ and $88.0 \%$. The prevalence of smoking was higher among female than among male Aboriginal youth (27.1\% v. 22.9\%; $p=0.03)$.

Table 1: Weighted characteristics of Aboriginal youth living off-reserve and non-Aboriginal youth, by sex

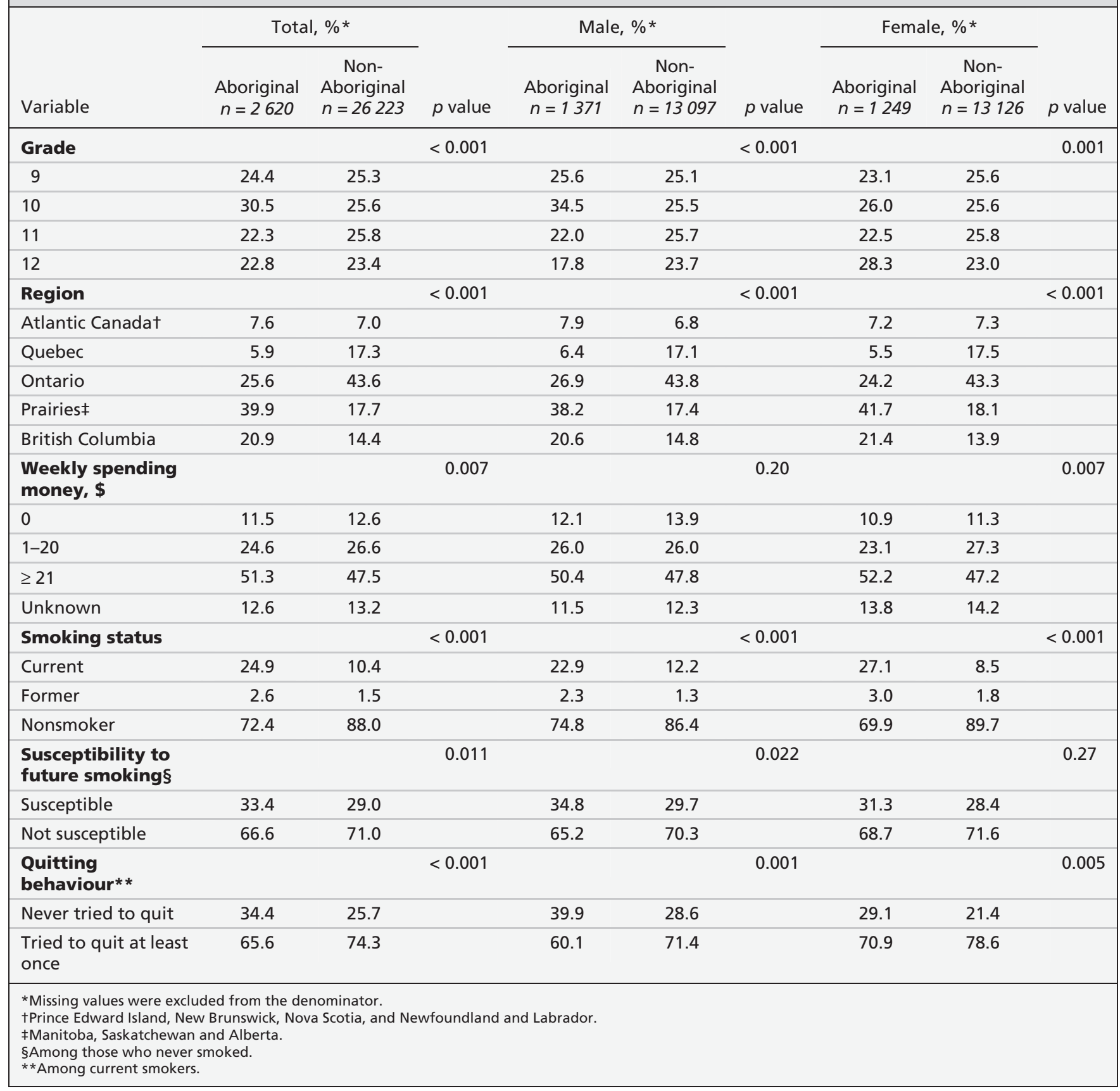


Among the respondents who reported having never smoked, $33.4 \%$ of Aboriginal youth and $29.0 \%$ of non-Aboriginal youth were identified as being susceptible to future smoking.

Among current smokers, $65.6 \%$ of Aboriginal youth and $74.3 \%$ of non-Aboriginal youth reported having tried to quit smoking. More female Aboriginals than male Aboriginals reported having made one or more attempts to quit (70.9\% v. $60.1 \% ; p=0.007)$.

The use of tobacco products other than cigarettes among the Aboriginal and non-Aboriginal respondents is shown in Figure 1. More Aboriginal youth than non-Aboriginal youth reported ever or currently using each type of tobacco product. Use of cigarillos or little cigars was especially higher among Aboriginal youth $(44.1 \%$ v. $29.8 \%)$, as was the use of flavoured cigarettes (41.9\% v. $27.0 \%)$.

\section{Exposure to second-hand smoke}

Exposure to second-hand smoke was more prevalent among the Aboriginal than the non-Aboriginal respondents (Table 2). For instance, 37.3\% of Aboriginal and $19.7 \%$ of non-Aboriginal youth reported exposure to second-hand smoke at home every day or almost every day; $51.0 \%$ of Aboriginal and $30.3 \%$ of non-Aboriginal youth reported exposure to second-hand smoke in cars on one or more days in the last week.

More female Aboriginals than male Aboriginals reported having been exposed to secondhand smoke in cars $(54.0 \%$ v. $48.1 \% ; p=0.02)$.

\section{Alcohol and drug use}

Most of the respondents reported having tried alcohol (88.5\% of Aboriginal and $84.2 \%$ of non-
Aboriginal youth) (Table 3). The average age at which they first tried alcohol was significantly lower among Aboriginal youth than among nonAboriginal youth (mean 12.5 [standard deviation (SD) 2.3] v. 13.1 [SD 2.3] years). Among those who ever tried alcohol, Aboriginal youth had a higher prevalence of binge drinking $(91.9 \% \mathrm{v}$. $85.2 \%$ among non-Aboriginals).

The prevalence of marijuana use was significantly higher among the Aboriginal youth than among the non-Aboriginal youth $(62.0 \% \mathrm{v}$. $41.1 \%$ ); the highest prevalence was among Aboriginal females $(64.1 \%)$. The prevalence of illicit drug use (excluding marijuana) was also higher among Aboriginal youth (34.8\% v. 20.6\%); again, female Aboriginals had the highest prevalence $(39.8 \%)$.

\section{Effect of Aboriginal status on key outcome variables}

For the logistic regression analysis to determine whether Aboriginal status predicted being a current smoker versus a nonsmoker (excluding former smokers), we controlled for sex, grade, weekly spending money and geographic region. We found that Aboriginal youth were more likely than non-Aboriginal youth to be current smokers (odds ratio [OR] 3.30, 95\% confidence interval [CI] 2.65-4.10). Among respondents who had never tried smoking (not even a puff) and controlling for the same variables, Aboriginals were no more or less likely than non-Aboriginals to be susceptible to future smoking (OR 1.20, 95\% CI 0.91-1.58). Among current smokers, Aboriginals were less likely than non-Aboriginals to have ever made an attempt to quit (OR $0.65,95 \%$ CI 0.43-0.96).

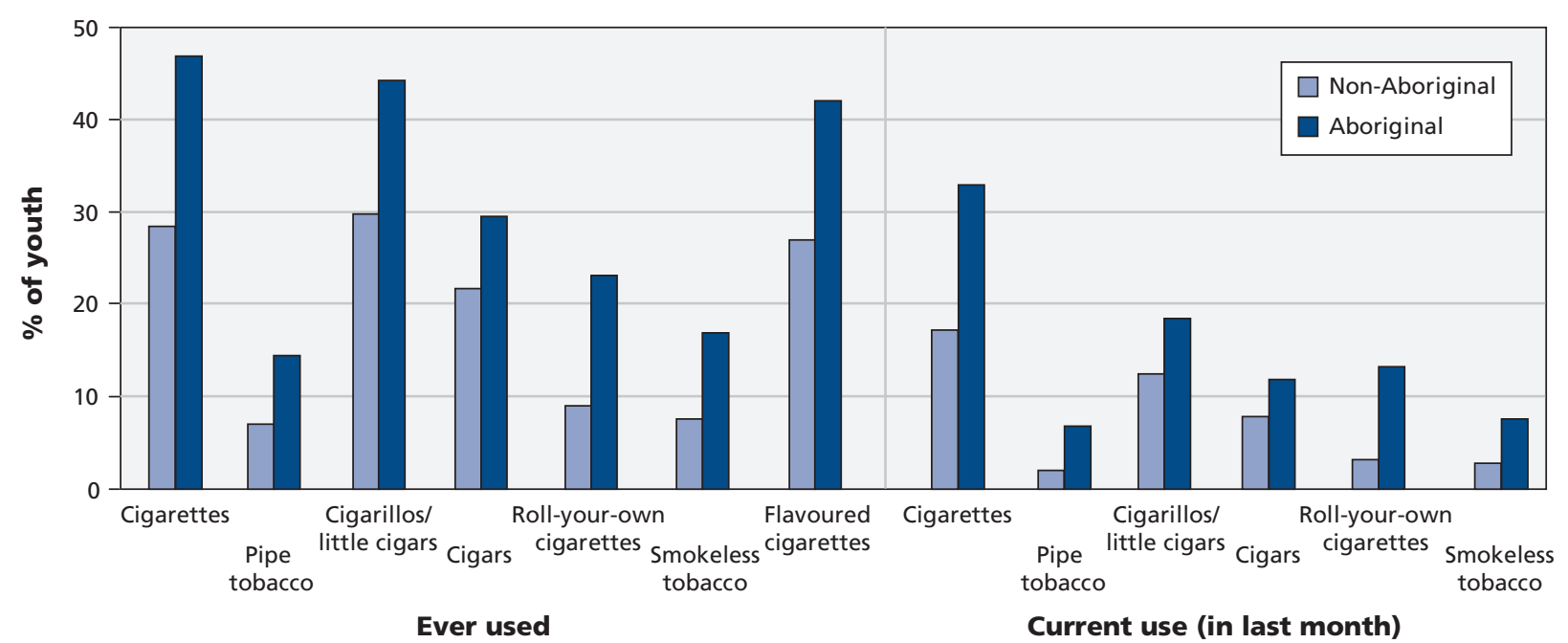

Figure 1: Use of tobacco products among 2620 Aboriginal youth living off-reserve and 26223 non-Aboriginal youth in grades 9 to 12. Current use of flavoured cigarettes is not shown because it was not included in the survey. Source: 2008/09 Youth Smoking Survey. ${ }^{9}$ 
In the remaining analyses, we controlled for sex, grade, geographic region, weekly spending money and smoking status (binary coded as current smoker v. nonsmoker, with former smokers excluded). We found that Aboriginal youth were more likely than non-Aboriginal youth to report being exposed to second-hand smoke at home every day or almost every day (OR $2.31,95 \% \mathrm{CI}$ 1.90-2.81). Aboriginal youth were also more likely to report being exposed to second-hand smoke in cars on one or more days in the last seven days (OR 2.04, 95\% CI 1.62-2.57). Aboriginals were more likely than non-Aboriginals to have ever tried marijuana (OR 2.06, 95\% CI 1.64-2.57) and other illicit drugs (OR 1.59, 95\% CI 1.25-2.02). Aboriginal youth were no more or less likely than non-Aboriginal youth to have drunk alcohol in the year before the survey (never had a drink / only had a sip v. all other categories) (OR 1.05, 95\% CI 0.86-1.29); they were more likely than non-Aboriginal youth to have engaged in binge drinking in the past year (OR 1.41, 95\% CI 1.09-1.83).

\section{Interpretation}

We found a consistent pattern in the data from the 2008/09 Youth Smoking Survey whereby Aboriginal youth living off-reserve in Canada were at significantly increased health risk as a function of their behavioural profile compared with non-Aboriginal youth. Aboriginal youth were more likely than non-Aboriginal youth to be current smokers, to report regular exposure to second-hand smoke, to have tried marijuana and other illicit drugs and to engage in binge drinking. Among current smokers, Aboriginal youth were less likely than non-Aboriginal youth to have tried to quit smoking. Among the Aboriginal youth, females had higher rates of current smoking, exposure to second-hand smoke, illicit drug use and frequency of drinking alcohol compared with males.

Self-identified Aboriginals comprise the fastest growing population in Canada. ${ }^{14}$ However, there is a paucity of research on the use of tobacco, alcohol and illicit drugs among Aboriginal youth in this country. Our results show that, consistent with previous studies involving Aboriginals living on reserve, Aboriginal youth living off-reserve are at increased health risk. Previous research summarizing tobacco, alcohol and illicit drug use among adolescents in Canada has not examined such use among Aboriginal youth and therefore may have underestimated the health risk to this population.

The differences that we observed between male and female Aboriginal youth in our study could be explained by differences in age. The female Aboriginal youth were older on average than the male Aboriginal youth and the nonAboriginal youth. Because youth are more likely to engage in risky behaviours as they get older, additional research is required to understand why female Aboriginal youth appear to be at increased risk for tobacco use and other risky behaviours.

Table 2: Exposure to second-hand smoke among Aboriginal youth living off-reserve and non-Aboriginal youth, by sex

\begin{tabular}{|c|c|c|c|c|c|c|c|c|c|}
\hline \multirow[b]{2}{*}{ Question } & \multicolumn{2}{|c|}{ Total, \%* } & \multirow[b]{2}{*}{$p$ value } & \multicolumn{2}{|c|}{ Male, \%* } & \multirow[b]{2}{*}{$p$ value } & \multicolumn{2}{|c|}{ Female, \%* } & \multirow[b]{2}{*}{$p$ value } \\
\hline & $\begin{array}{c}\text { Aboriginal } \\
n=2620\end{array}$ & $\begin{array}{l}\text { Non- } \\
\text { Aboriginal } \\
n=26223\end{array}$ & & $\begin{array}{c}\text { Aboriginal } \\
n=1371\end{array}$ & $\begin{array}{l}\text { Non- } \\
\text { Aboriginal } \\
n=13097\end{array}$ & & $\begin{array}{c}\text { Aboriginal } \\
n=1249\end{array}$ & $\begin{array}{l}\text { Non- } \\
\text { Aboriginal } \\
n=13126\end{array}$ & \\
\hline \multicolumn{3}{|c|}{$\begin{array}{l}\text { Excluding yourself, how many people } \\
\text { smoke inside your home every day or } \\
\text { almost every day? }\end{array}$} & $<0.001$ & & & $<0.001$ & & & $<0.001$ \\
\hline 0 & 62.7 & 80.3 & & 63.5 & 80.2 & & 61.8 & 80.3 & \\
\hline 1 & 12.4 & 10.4 & & 11.1 & 10.2 & & 13.8 & 10.7 & \\
\hline 2 & 13.9 & 6.2 & & 14.9 & 6.1 & & 12.8 & 6.3 & \\
\hline$\geq 3$ & 11.0 & 3.1 & & 10.5 & 3.5 & & 11.6 & 2.7 & \\
\hline \multicolumn{3}{|c|}{$\begin{array}{l}\text { During the last seven days, on how } \\
\text { many days did you ride in a car with } \\
\text { someone who was smoking cigarettes? }\end{array}$} & $<0.001$ & & & $<0.001$ & & & $<0.001$ \\
\hline 0 & 49.0 & 69.7 & & 51.9 & 69.8 & & 46.0 & 69.6 & \\
\hline $1-2$ & 23.3 & 16.0 & & 22.3 & 16.1 & & 24.4 & 15.8 & \\
\hline $3-6$ & 15.9 & 8.8 & & 13.9 & 8.3 & & 18.0 & 9.4 & \\
\hline 7 & 11.8 & 5.5 & & 12.0 & 5.7 & & 11.6 & 5.2 & \\
\hline
\end{tabular}




\section{Limitations}

Our study has limitations. The data were selfreported, which may be subject to recall bias, and we were unable to use biological measures to confirm responses. However, we have no reason to believe that recall should differ between Aboriginal and non-Aboriginal youth. For socioeconomic status, we used a proxy measure based on the respondents' reported weekly spending money rather than parental or household income measures. Household income measures are not included in the Youth Smoking Survey because it is unclear whether adolescents are able to accurately report household income.

\section{Implications for policy and research}

The high prevalence of smoking and use of other substances among Aboriginal youth living offreserve highlights the need for culturally appropriate smoking cessation and substance prevention programs that target Aboriginal youth. Because previous research has shown the comorbid use of alcohol, tobacco and marijuana to be prevalent among Canadian youth, ${ }^{10}$ it may also be warranted to develop and evaluate prevention efforts targeting Aboriginal youth that address multiple risk factors. Such strategies should address the unique strengths and needs of Aboriginal youth, as was done with programs successfully adopted in other domains (e.g., the treatment of solvent abuse)..$^{15,16}$

Table 3: Use of alcohol and drugs among Aboriginal youth living off-reserve and non-Aboriginal youth, by sex

\begin{tabular}{|c|c|c|c|c|c|c|c|c|c|}
\hline \multirow[b]{2}{*}{ Question } & \multicolumn{2}{|c|}{ Total, \%* } & \multirow[b]{2}{*}{$p$ value } & \multicolumn{2}{|c|}{ Male, \%* } & \multirow[b]{2}{*}{$p$ value } & \multicolumn{2}{|c|}{ Female, \%* } & \multirow[b]{2}{*}{$p$ value } \\
\hline & $\begin{array}{l}\text { Aboriginal } \\
n=2620\end{array}$ & $\begin{array}{l}\text { Non- } \\
\text { Aboriginal } \\
n=26223\end{array}$ & & $\begin{array}{l}\text { Aboriginal } \\
n=1371\end{array}$ & $\begin{array}{l}\text { Non- } \\
\text { Aboriginal } \\
n=13097\end{array}$ & & $\begin{array}{c}\text { Aboriginal } \\
n=1249\end{array}$ & $\begin{array}{l}\text { Non- } \\
\text { Aboriginal } \\
n=13126\end{array}$ & \\
\hline \multicolumn{3}{|c|}{$\begin{array}{l}\text { In the last year, how often did you have a drink } \\
\text { of alcohol that was more than just a sip? }\end{array}$} & $<0.001$ & & & $<0.001$ & & & $<0.001$ \\
\hline Never drank alcohol & 11.5 & 15.8 & & 13.8 & 16.1 & & 8.9 & 15.4 & \\
\hline Not in the last year & 5.0 & 4.2 & & 5.4 & 4.4 & & 4.6 & 4.0 & \\
\hline A sip & 11.6 & 13.4 & & 12.9 & 11.6 & & 10.2 & 15.3 & \\
\hline$<$ once a month & 11.8 & 17.1 & & 10.8 & 16.2 & & 13.0 & 18.0 & \\
\hline$\geq$ once a month & 60.1 & 49.6 & & 57.1 & 51.7 & & 63.4 & 47.3 & \\
\hline \multicolumn{3}{|c|}{$\begin{array}{l}\text { How old were you when you first had a drink } \\
\text { of alcohol that was more than a sip?t }\end{array}$} & $<0.001$ & & & 0.027 & & & $<0.001$ \\
\hline Age, yr mean (SD) & $12.5(2.3)$ & $13.1(2.3)$ & & $12.3(2.4)$ & $12.8(2.5)$ & & $12.7(2.1)$ & $13.3(2.0)$ & \\
\hline \multicolumn{3}{|c|}{$\begin{array}{l}\text { In the last year, how often did you have five } \\
\text { or more drinks of alcohol on one occasion?t }\end{array}$} & $<0.001$ & & & $<0.001$ & & & $<0.001$ \\
\hline Never & 8.1 & 14.8 & & 9.0 & 15.1 & & 7.2 & 14.6 & \\
\hline Not in the last year & 8.5 & 11.4 & & 9.2 & 10.2 & & 7.8 & 12.7 & \\
\hline$<$ once a week & 53.6 & 54.4 & & 49.6 & 52.0 & & 57.8 & 57.0 & \\
\hline$\geq$ once a week & 29.8 & 19.4 & & 32.2 & 22.7 & & 27.2 & 15.8 & \\
\hline \multicolumn{3}{|c|}{$\begin{array}{l}\text { In the last year, how often did you use marijuana } \\
\text { or cannabis? (a joint, pot, weed, hash ...) }\end{array}$} & $<0.001$ & & & $<0.001$ & & & $<0.001$ \\
\hline Never & 38.0 & 58.9 & & 39.9 & 55.8 & & 35.9 & 62.1 & \\
\hline Not in the last year & 8.7 & 6.6 & & 7.2 & 5.9 & & 10.5 & 7.5 & \\
\hline < once a week & 20.7 & 19.7 & & 17.3 & 19.5 & & 24.5 & 20.0 & \\
\hline$\geq$ once a week & 32.5 & 14.8 & & 35.6 & 18.8 & & 29.1 & 10.5 & \\
\hline \multicolumn{3}{|c|}{$\begin{array}{l}\text { How old were you when you first used } \\
\text { marijuana or cannabis?† }\end{array}$} & $<0.001$ & & & $<0.001$ & & & $<0.001$ \\
\hline Age, yr, mean (SD) & $12.8(2.2)$ & $14.0(1.9)$ & & $12.7(2.3)$ & $13.9(2.1)$ & & $13.0(2.1)$ & $14.1(1.6)$ & \\
\hline Did you ever use illicit drugs?ł & & & $<0.001$ & & & $<0.001$ & & & $<0.001$ \\
\hline Yes & 34.8 & 20.6 & & 29.6 & 21.2 & & 39.8 & 20.0 & \\
\hline No & 65.2 & 79.4 & & 70.4 & 78.8 & & 60.2 & 80.0 & \\
\hline \multicolumn{10}{|c|}{$\begin{array}{l}\text { Note: SD = standard deviation. } \\
\text { *Unless stated otherwise. For percentages, missing values were excluded from the denominator. } \\
\text { tAmong those who ever tried. } \\
\text { fExcludes marijuana use. }\end{array}$} \\
\hline
\end{tabular}


Most of the Aboriginal youth who identified themselves as current smokers, particularly females, reported that they had tried to quit at least once previously. This finding suggests that Aboriginal youth are interested in quitting but have not been successful and that they may require additional support to stop smoking. Primary care physicians and other health practitioners should be encouraged to screen for smoking status, particularly among Aboriginal youth. Health practitioners should also provide information to parents regarding the harmful effects of exposure to second-hand smoke and the benefits of having a smoke-free home. There is also a need for tobacco control policies and programs that address exposure to second-hand smoke among Aboriginal youth.

\section{Conclusion}

Current national estimates of smoking, and alcohol and illicit drug use among youth underestimate the prevalence of these behaviours among Aboriginal youth living off-reserve. Our findings highlight the need for culturally appropriate prevention and cessation policies and programs for this at-risk population.

\section{References}

1. First Nations Centre. First Nations Regional Longitudinal Health Survey 2002/03: results for adults, youth and children living in First Nations communities. Ottawa (ON): National Aboriginal Health Organization: 2005. Available: www.fnigc.ca/sites/default /files/ENpdf/RHS_2002/rhs2002-03-technical_report.pdf (accessed 2011 Apr. 8).

2. Hutchinson PJ, Richardson CG, Bottorff JL. Emergent cigarette smoking, correlations with depression and interest in cessation among Aboriginal adolescents in British Columbia. Can J Public Health 2008;99:418-22.

3. Johnson JL, Tucker RS, Ratner PA, et al. Socio-demographic correlates of cigarette smoking among high school students: results from the British Columbia Youth Survey on Smoking and Health. Can J Public Health 2004;95:268-71.

4. Tu AW, Ratner PA, Johnson JL. Gender differences in correlates of adolescents' cannabis use. Subst Use Misuse 2008;43:1438-63.

5. Young TK. Review of research on aboriginal populations in Canada: relevance to their health needs. BMJ 2003;327:419-22.

6. Aboriginal peoples in Canada in 2006: Inuit, Métis and First Nations, 2006 census. First Nations people. Ottawa (ON): Statistics Canada; 2002. Available: www12.statcan.ca/census-recensement 12006/as-sa/97-558/p16-eng.cfm (accessed 2010 Nov. 10).

7. Tjepkema M. The health of the off-reserve Aboriginal population. Health Rep 2002;13(Suppl):1-16.
8. Federal Tobacco Control Strategy. Ottawa (ON): Health Canada; 2009. Available: www.hc-sc.gc.ca/hc-ps/tobac-tabac/about -apropos/role/federal/strateg-eng.php (accessed 2010 Nov. 10).

9. 2008/2009 Youth Smoking Survey results. Waterloo (ON): Propel Centre for Population Health Impact; 2010. Available: www.yss .uwaterloo.ca/index.cfm?section $=5 \&$ page $=288$ (accessed 2011 Apr. 8).

10. Leatherdale ST, Ahmed R. Alcohol, marijuana and tobacco use among Canadian youth: Do we need more multi-substance prevention programming? J Prim Prev 2010;31:99-108.

11. Leatherdale ST, Ahmed R. Second-hand smoke exposure in homes and in cars among Canadian youth: current prevalence, beliefs about exposure, and changes between 2004 and 2006. Cancer Causes Control 2009;20:855-65.

12. Leatherdale ST, Hammond D, Ahmed R. Alcohol, marijuana, and tobacco use patterns among youth in Canada. Cancer Causes Control 2008;19:361-9.

13. Pierce JP, Choi WS, Gilpin EA, et al. Validation of susceptibility as a predictor of which adolescents take up smoking in the United States. Health Psychol 1996;15:355-61.

14. Aboriginal peoples in Canada in 2006: Inuit, Métis and First Nations, 2006 census. Aboriginal people surpass the one-million mark. Ottawa (ON): Statistics Canada; 2006. Available: www12 .statcan.ca/census-recensement/2006/as-sa/97-558/p2-eng.cfm (accessed 2010 Nov. 10).

15. Crooks CV, Chiodo D, Thomas D. Engaging and empowering Aboriginal youth: a toolkit for service providers. 2009. Available: www.bchealthycommunities.ca/Images/Newsletter /engaging\%20and $\% 20$ empowering $\% 20$ Aboriginal $\% 20$ youth $\%$ 20pre-pub\%20(2).pdf (accessed 2011 Mar. 1).

16. Crooks CV, Chiodo D, Thomas D, et al. Strengths-based programming for First Nations youth in schools: building engagement through healthy relationships and leadership skills. Int J Ment Health Addict 2010;8:160-73.

Affiliations: From the Propel Centre for Population Health Impact (Elton-Marshall, Burkhalter), Canadian Cancer Society/University of Waterloo, Waterloo, Ont.; and the Department of Prevention and Cancer Control (Leatherdale), Cancer Care Ontario, Toronto, Ont.

Contributors: Tara Elton-Marshall and Scott Leatherdale contributed substantially to the conception and design of the study. All of the authors contributed to the analysis and interpretation of the data. Tara Elton-Marshall drafted the article, and Scott Leatherdale and Robin Burkhalter revised the article critically for important intellectual content. All of the authors gave final approval of the version to be published.

Funding: The 2008/09 Youth Smoking Survey is a product of a pan-Canadian capacity-building project that includes Canadian researchers from all provinces and provides training opportunities for university students at all levels. Production of this paper was made possible through a financial contribution from Health Canada. The views expressed herein do not necessarily represent the views of Health Canada.

Acknowledgements: The authors thank the Propel Centre for Population Health Impact for providing support for this project. Scott Leatherdale is a Cancer Care Ontario Research Chair in Population Studies. 